\title{
Density dependent regulation of fecundity in Syngamus trachea populations in semi-naturally occurring ring-necked pheasants (Phasianus colchicus) and wild Carrion Crows (Corvus corone).
}

by Gethings, O.J., Sage, R.B. and Leather, S.R.

Copyright, Publisher and Additional Information: Author's accepted manuscript published by Cambridge Journals in Parasitology:

DOI: $10.1017 /$ S0031182016000135

A note on versions:

The version presented here may differ from the published version or, version of record, if you wish to cite this item you are advised to consult the publisher's version.

Harper Adams

University

Gethings, O.J., Sage, R.B. and Leather, S.R. 2016. Density dependent regulation of fecundity in Syngamus trachea populations in semi-naturally occurring ring-necked pheasants (Phasianus colchicus) and wild Carrion Crows (Corvus corone). Parasitology, 143 (6), pp. 716-722. 
1 Density dependent regulation of fecundity in Syngamus trachea populations in semi2 naturally occurring ring-necked pheasants (Phasianus colchicus) and wild Carrion Crows 3 (Corvus corone).

O J Gethings ${ }^{1}$, R B Sage ${ }^{2}$ and S R Leather ${ }^{1}$

${ }^{1}$ Department of Crop \& Environment Sciences, Harper Adams University, Edgmond, Newport, TF10 8NB UK;

${ }^{2}$ Game \& Wildlife Conservation Trust, Burgate Manor, Fordingbridge, SP6 1EF, UK.

9

\section{Keywords}

\section{ABSTRACT}

Previous work has highlighted increased opportunities for the transmission of Syngamus trachea within pheasant release pens, due in part to the highly aggregated distribution of the infectious stages around feed hoppers and communal areas. Despite this, the distribution of adult worms within their definitive hosts is not significantly different from predicted distributions under Taylor's power law. Therefore, density-dependent processes are probably acting to regulate $S$. trachea population dynamics. Patterns of nematode fecundity and parasite establishment were investigated in a semi-naturally occurring population of ring-necked pheasants (Phasianus colchicus) and a wild population of carrion crows (Corvus Carone).

Worm length was a reliable indicator of nematode fecundity, and an inverse relationship between mean worm length and mean worm burden was identified within both species. The stunting of worms at greater parasite densities was present in both immunologically naïve and previously exposed pheasants, so is unlikely to be a function of age-dependent acquired immunity. Interestingly, the effect of parasite crowding on mean worm length was stronger in the crow population, apparently driven by a greater mean worm burden when compared with pheasants. The findings of the present study are in agreement with previous work that pheasants do indeed develop immunity to $S$. trachea, however nematode length and fecundity appear to be a function of parasite density, and therefore parasite-mediated competition and not host-mediated heterogeneities in immunocompetence.

\section{Syngamus trachea; density dependence; Pheasant; Crow; Fecundity; Worm length; immunity}




\section{Introduction}

One recurring theme within parasite ecology is the relative stability of parasite populations in domestic and wild animal hosts (Anderson \& May, 1978; Tompkins \& Hudson, 1999), which suggests that some form of regulatory mechanism must be ensuring population stability. The majority of these mechanisms are driven by parasite density, i.e. are a function of mean parasite burden within individual hosts; thus acting on infra-populations as opposed to populations as a whole. Indeed, density-dependent regulatory mechanisms act on many aspects of the parasite lifecycle, such as parasite establishment, growth, fecundity, development and maturation times, and adult survival (Walker et al., 2009). Growth and fecundity for instance, being the two most common aspects of the life cycle regulated by such mechanisms in helminth populations (Tompkins \& Hudson, 1999), are particularly important at regulating the abundance of the 'freeliving', infectious stages within the environment, and therefore determining the extent of future infections. These density-dependent mechanisms are important for regulating and stabilising transmission dynamics, and therefore the parasite-host relationship, by ensuring that infrapopulations do not become too over or underdispersed.

Despite knowledge of the existence of such regulation, the mechanisms underlying densitydependence are poorly understood, as it is difficult to disentangle host and parasite responses to increasing parasite challenge (Paterson \& Viney, 2002). Host immune responses have been demonstrated to reduce establishment, survivability and fecundity of parasitic nematodes, and it is hypothesised that innate and adaptive immune responses, whose response to infection increases with increasing parasite density, are responsible for the manifestation of density dependence (Paterson \& Viney, 2002). Similarly, intraspecific competition for space and resources once inside the host has also been implicated as a driver of density-dependent regulation. Indeed, Michael and Dunby (1989), hypothesised that parasite-mediated competition was responsible for Trichuris muris establishment in the mouse, owing to the finite carrying-capacity of the caecum.

Syngamus trachea is a parasitic nematode occurring in a wide range of avian hosts (Gethings et al., 2015a;b). The non-specific nature of this parasite makes it possible to study differences in host-mediated responses to a natural challenge of $S$. trachea. In a previous paper by Gethings et al. (2015b), we highlighted the fact that despite increased opportunities for transmission of $S$. trachea within pheasant release pens, relatively low numbers of adult worms are consistently recovered upon post-mortem investigation. This is often the case in experimental infections using large numbers of infective larvae (Olivier, 1944; Guildford \& Herrick, 1954). Despite these previous studies finding relationships between $S$. trachea establishment and host immunity, no such work 
has been conducted in semi-naturally occurring pheasant populations using natural infections of $S$. trachea. The aims of the present study were to determine firstly, whether worm length is a good indicator of fecundity within $S$. trachea populations, and secondly, to determine whether fecundity is impaired in response to increasing worm burden.

\section{Materials and Method}

\subsection{Pheasants}

Male and female ring-necked pheasants (Phasianus colchicus) were recovered from two pheasant estates in the South West of England from January 2014 to November 2015. All birds were either obtained during the shooting season or were found dead on the estates at various times of the year.

\subsection{Corvids}

Crows were opportunistically sampled throughout the season, as the sites were undertaking Corvid control via the use of Larsen traps. Crows and Rooks are known to be commonly infected with $S$. trachea, and any density-dependent effects would likely be more apparent as worm burdens tend to be larger than in pheasants. Age was roughly estimated by presence/absence and size of the bursa of fabricius, which has usually atrophied by 6 months (Williams \& Newton, 1969); however no formal analysis of the effects of age on either parasite burdens or length was undertaken during this study.

\subsection{Adult worm recovery}

Adult Syngamus trachea worms were recovered from the trachea of pheasants and crows. The trachea was first resected from the underlying connective tissue and transected slightly above the proximal bifurcation of the bronchi. The trachea was then incised longitudinally through the tracheal cartilage and the worms recovered using fine-tipped forceps. Adult worms were distinguished from juvenile (L4) worms by observation under a microscope at varying magnifications in order to detect the presence of fertilised ova. Adult worms from both species were assessed according to Lewis (1928), which confirmed that these worms were indeed $S$. trachea and that the worms were identical between species justifying the between-species comparisons. 


\subsection{Worm length and fecundity}

105 Fernando et al. (1971) conducted in-depth pathogenetic examinations detailing adult worm length 106 at various stages of development, and determined the number of days post-infection (PI) to the 107 production of fertilised ova. Female S. trachea worms are fertile by day 14 PI, with minimum 108 female length at the adult stage generally averaging 10-15mm. Once fertile, Guildford and Herrick 109 (1954) found no relationship between days PI and female worm length, so we concluded that the 110 number of days PI was not a significant confounding factor within this study. As several authors

111 have demonstrated that worm length is significantly correlated with worm fecundity (Michael \& 112 Dunby, 1989; Stear et al., 1997; Stear \& Bishop, 1999; Tompkins \& Hudson, 1999; Walker et al., 113 2009), the same principle was applied in this study. One hundred female worms were selected at 114 random in order to estimate the effect of length on the number of eggs per worm. Each female 115 worm was measured using a digital calliper (accuracy to $0.01 \mathrm{~mm}$ ) and the number of eggs were 116 counted using a stereomicroscope. In order to ensure egg viability, eggs were recovered from each 117 worm and maintained in the laboratory at $24 \circ \mathrm{C}$ (Wehr, 1937). Eggs were cultured to the infective 118 stage (L3) and manually hatched by applying light pressure between two cover slips.

\subsection{Condition of the trachea}

122 It has been demonstrated that prolonged infections with S. trachea result in the formation of 123 hyperplastic tracheal cartilage in which the adult male worms are deeply embedded (Clapham, 124 1935). These nodules begin to form between 26 and 37 days PI and generally remain indefinitely; 125 meaning previous exposure and current infection length can be determined. To assess whether 126 previous exposure influenced mean worm length or mean worm burden in subsequent infections, 127 pheasant tracheas were examined for the present of nodules. These nodules do not form at the 128 point of attachment in corvids so previous exposure cannot be determined. Therefore, crows were 129 excluded from this part of analysis.

\subsection{Statistical analysis}

133 All data were analysed using the $\mathrm{R}$ statistical package for Macintosh. The Mean number of worms 134 per bird and the mean number of eggs per female worm were transformed before analysis to 135 normalise the distribution by applying $\log (+1)$ transformation. Differences in the mean number of worms and mean worm length between species were assessed using Welch's $t$-test for unequal samples. The effect of parasite burden on mean parasite length was assessed using linear regression analysis using the $l m$ function in R. In order to determine the minimum parasite density 
at which negative effects are observable, iterative backwards-stepwise deletion of the highest parasite densities was conducted until the regression was no longer significant at the $P=<0.05$ level.

\subsection{Results}

The trachea of 38 pheasants and 92 crows were recovered and examined for the presence of adult S. trachea worms, of which 1307 pairs were recovered.

\subsection{Worm length and number of eggs}

In-utero egg counts were performed on 106 adult female worms recovered from 10 crows and 10 pheasants, with an average $( \pm$ SEM) of $1066( \pm 41.5)$. Worm length explained $86.2 \%$ of the variation in the number of eggs per female worm, even after controlling for the number of worms per trachea $\left(F_{1,102}=646.5, R^{2}=0.862, p=<0.001\right)$.

\subsection{Worm length and parasite intensity}

Mean worm length was significantly correlated with parasite density for both pheasants and crows, with a significant reduction in mean worm length at higher parasite densities $\left(F_{1,127}=\right.$ 393.3, $R^{2}=0.759, P=<0.001$ ) (Fig.1). For individual species, there was a stronger effect of mean worm burden on mean worm length for crows $\left(F_{1,90}=340.2, R^{2}=0.79, p=<0.001\right)$ than for pheasants $\left(F_{1,35}=64.21, R^{2}=0.64, p=<0.001\right)$. Stepwise data-point deletion of the highest parasite densities revealed that density-dependent effects begin to manifest above 4 worms per bird for pheasants, and 2 worms per bird for crows, with the regression model not reaching the significance level of $p<0.05$ below 5 worms per host.

\subsection{Trachea length}

The length of the trachea did not influence either the mean number of worms per bird or mean worm length for either species.

\subsection{Presence of nodules, mean worm length and number of adult worms}

Crows were excluded from this part of analysis so results are not reported. Retrospective analysis of the Guildford and Herrick (1954) data, and trachea condition in the present study revealed that pheasants with hyperplastic tracheal nodules tended to have fewer adult worms present in the trachea (Mean $\pm \mathrm{SEM}=5.45 \pm 1.16$ worms per bird) than birds without nodules (Mean $\pm \mathrm{SEM}=$ $10.36 \pm 1.29$ worms per bird) $\left(n=31, t^{28}=3.45, p=<0.001\right)$. Interestingly, female worms in birds with evidence of previous exposure tended to be longer (Mean $\pm \mathrm{SEM}=15.42 \mathrm{~mm} \pm 0.73$ ) when 
174 compared with worms in birds that had no evidence of previous exposure (Mean $\pm \mathrm{SEM}=10.43$

$175 \mathrm{~mm} \pm 0.79)\left(n=23, t^{13}=-3.13, p=<0.001\right)$.

176

177

3.5 Mean worm length and mean worm burden between species

178 The mean number of adult worms per trachea differed significantly between species, with crows 179 having a mean worm burden of $11.17( \pm \mathrm{SEM}=0.10)$ and pheasants having an average of $7.54( \pm$ $180 \mathrm{SEM}=1.39)$ worms per trachea $\left(t^{72.14}=2.02, p=0.04\right)$. Similarly, mean worm length differed 181 significantly between species, with pheasants having a mean worm length of $17.97 \mathrm{~mm}( \pm \mathrm{SEM}=$ $1820.85)$ and crows having a mean worm length of $15.55 \mathrm{~mm}( \pm \mathrm{SEM}=0.55)\left(t^{66.58}=2.34, p=0.02\right)$. 183

184

185

186

187

188

189

190

191

192

193

194

195

196

197

198

199

200

201

202

203

204

205

206

207

208 
213 Density-dependent reductions in worm size and fecundity have been reported in a large number of 214 studies (Michael \& Dunby, 1989; Stear et al., 1997; Stear \& Bishop, 1999; Tompkins \& Hudson, 215 1999; Walker et al., 2009), and density-dependent reductions in worm length, but not necessarily 216 fecundity, are reported in practically all nematode species (Mossinger \& Wenk, 1986; Szalai \& 217 Dick, 1989; Sinniah \& Subramaniam, 1991; Skorping et al., 1991; Marcogliese, 1997; Dezfuli et 218 al., 2002; Irvine et al. 2001; Richards \& Lewis, 2001). A vast majority of studies concerning 219 density dependence have been laboratory-based experimental infections, which do not accurately 220 represent conditions facing free-living wild animal populations in terms of parasite load and 221 encounter rates. The present study provides reliable information concerning apparent density222 dependent regulation of fecundity in both an intensively-managed pheasant population, and a free223 living wild population of corvids. Although the fact that immune status is responsible for 224 regulating the establishment of $S$. trachea in ring-necked pheasants is not novel, this is first 225 mention of both parasite and host-mediated factors regulating $S$. trachea populations in any bird 226 species.

In agreement with previous studies (Olivier, 1944; Guildford and Herrick, 1954), immune function is responsible for the establishment of $S$. trachea within the ring-necked pheasant. This is demonstrated by a reduction in parasite abundance in birds that had evidence of previous exposure. There was however, a trend for greater numbers of adult worms in crows, which suggests that worm establishment is not constrained by size or length of the trachea, and therefore overall host size, however is perhaps a function of host immunity. Indeed, Olivier (1944), found that $S$. trachea establishment was dose dependent. He found that the number of worms establishing was inversely proportional to the size of the infective dose, and attributed this to the strength of the immune response (Olivier, 1944). This result is in stark contrast to the findings of Michael and Dunby (1989), who found that Trichuris muris establishment in the murine host is believed to be regulated by density-dependent infraspecific competition, owing to the finite space in the caecum. It is unlikely however, that $S$. trachea establishment is regulated in a similar manner as more worms have been found in crows with a shorter trachea, and there was no relationship between trachea length and mean worm burden. This apparent immune-mediated inhibition on worm establishment has also been identified for $S$. trachea in chickens, with a lower mean worm burden generally identified in older, previously exposed chickens (Crawford, 1940). If 
establishment was merely a result of parasite-mediated competition, worm establishment, and therefore burden, would be similar in both immunological naïve and previously exposed birds (Luong et al., 2011).

One reason to explain the trend for higher worm abundance in crows is acquired-immunity. Pheasants are known to develop moderate immunity to $S$. trachea, however, no such work has been conducted in wild crow populations. Being a known reservoir for S. trachea, it may be that crows have a higher parasite threshold for the stimulation of an immune response or they do not develop significant immunity to subsequent infections. Indeed, pheasants appear to be more susceptible to infection early on in the rearing process, whereas $\mathrm{S}$. trachea adults have been recovered from crows of varying ages (Personal unpublished data). Further work is however, required in order to determine whether wild crows develop any immunity to $S$. trachea.

Although density-dependent reduction of worm fecundity was present in both species, the fact that the effect of crowding on mean worm length was more profound within the crow population is interesting. Mean worm burden explained $82 \%$ of the variation in mean worm length in crows, compared with $64 \%$ in pheasants, with crows having a tendency for a greater mean worm burden when compared with pheasants. Even so, the fact that worms tended to be shorter in crows, in response to higher mean worm burdens, suggests that these effects are indeed density-dependent. The inverse relationship between worm length and worm burden was present in both species, and appears to be a result of parasite-mediated competition, for either space or resources. Indeed, these effects were even observed in pheasants with no history of previous exposure. Similarly, as there was a vast number of birds of different ages, it is unlikely that age-dependent acquired-immunity was responsible for the manifestation of density dependence within these birds, as the effects were identified in juveniles, as well as adult birds, with little to no acquired immunity. Conversely, Paterson and Viney (2002), observed the absence of density-dependent mechanisms at regulating survivability and fecundity of Strongyloides ratti infra-populations in immuno-compromised

271 hosts. These mechanisms were however, present in later primary infections, suggesting that host mediated heterogeneities in immuno-competence are regulating population dynamics before

274 (Paterson \& Viney, 2002). Alternatively, worm length has been shown to be related to levels of local parasite-specific immunoglobulin A (IgA) (Stear et al., 1997). These responses are however, often absent in immunologically-naïve animals, and only generally manifest in animals that have

277 been previously exposed (Craig et al., 2014) so it is unlikely to be occurring within these study populations. 
The parasite threshold for the manifestation of density-dependence within this study was low 280 compared with other studies. For instance, the threshold for density-dependent reductions in 281 fecundity in the caecal nematode, Heterakis gallinarum, in pheasants is 96 worms (Tomkins \& 282 Hudson, 1999). Similarly, this threshold for Tricostrongylus colubriformis in sheep is around 3000 worms per host (Dobson et al., 1990). It is generally believed that density-dependent effects are of greater importance for parasites that are large compared with their host (Poulin \& Morand, 2000). Indeed, $S$. trachea adults can grow up to $\sim 33 \mathrm{~mm}$ in length in an $80-100 \mathrm{~mm}$ long trachea (Crow). In comparison, mean worm length of Heterakis gallinarum adults in the cecae of pheasants is around $9.64 \mathrm{~mm}( \pm 0.11)$ (Tompkins \& Hudson, 1999), in caecae ranging from 240.11 for male and 213.84 for female pheasants respectively. Similarly, Pterygodermatites peromysci, a nematode parasite of mice, is regulated by tight density-dependent restrictions on the number and length of adult worms in the small intestine (Luong et al., 2011). Similarly to S. trachea, P. peromysci can grow up to $33 \mathrm{~mm}$ in a $250 \mathrm{~mm}$ mouse intestine (Luong et al., 2011).

The findings of the present study are in agreement with previous work that pheasants do indeed develop immunity to S. trachea (Olivier, 1944; Guildford \& Herrick, 1954), however nematode length and fecundity appear to be a function of parasite density, and therefore parasite-mediated competition and not host-mediated heterogeneities in immunocompetence. 
References

Anderson, R.M. \& May, R.M. (1978). Regulation and stability of the host-parasite population interactions. Journal of Animal Ecology. 47, 219-247.

Clapham, P.A. (1935). On Nodules occasioned by Gapeworm in Pheasants. Journal of Helminthology. 13, 9-12.

Craig, N.M., Smith, D.W., Pate, J.A., Morrison, I.W., Knight, P.A. (2014). Local cytokine transcription in naïve and previously infected sheep and lambs following challenge with Teladorsagia circumcincta. BMC Veterinary Research. 10. doi:10.1186/1746-6148-10-87.

Crawford, M. (1940). Infection of adult fowls with Syngamus trachealis. Indian Journal of Veterinary Science and Animal Husbandry. 10, 293-294.

Dezfuli, B.S., Volponi, S., Beltrami, I., Poulin, R. (2002). Intra- and interspecific densitydependent effects on growth in helminth parasites of the cormorant, Phalacrocorax carbo sinensis. Parasitology. 124, 537-544.

Dobson, A. P., Waller, P. J. \& Donald, A. D. (1990). Population dynamics of Trichostrongylus colubriformes in sheep: the effect of infection rate on the establishment of infective larvae and parasite fecundity. International Journal for Parasitology 20, 347-352.

342 Fernando, M.A., Stockdale, P.H.G., Remmler, O. (1971). The route of migration, 343 development and pathogenesis of Syngamus trachea (Motagu, 1811), Chapin 1925, in 344 Pheasants. The Journal of Parasitology. 57, 107-116. 
346 Gethings, O.J., Sage, R.B., Leather, S.R., 2015a. Spatio-temporal factors influencing the 347 occurrence of Syngamus trachea within release pens in the South West of England. Veterinary 348 Parasitology. 207, 64-71.

Gethings, O.J., Sage, R.M., Leather, S.R. (2015b). Spatial distribution of the infectious stages of the nematode Syngamus trachea within release pens in the South West of England: Potential density dependence? Veterinary Parasitology. doi:10.1016/j.vetpar.2015.07.016.

Guilford, H. G. \& Herrick, C. A. (1954). The effect of gapeworm disease in pheasants. Transactions of the Wisconsin Academy of Sciences Arts and Letters. 43 25-50

Irvine, R. J., Stien, A., dallas, J. F., Halvorsen, O., Langvatn, R. \& Albon, S. D. (2001). Contrasting regulation of fecundity in two abomasal nematodes of Svalbard reindeer (Rangifer tarandus platyrhynchus). Parasitology 122, 673-681.

Lewis, A. (1928). Observations on the Morphology of Syngamus trachea from some Wild and Domestic Birds. Journal of Helminthology. 6, 99-112.

Luong, L.T., Vigliotti, B.A., Hudson, P.J. (2011). Strong density-dependent competition and acquired immunity constrain parasite establishment: Implications for parasite aggregation. International Journal for Parasitology. 41, 505-511.

Marcogliese, D. J. (1997). Fecundity of sealworm (Pseudoterranova decipiens) infecting grey seals (Halichoerus grypus) in the Gulf of St. Lawrence, Canada: lack of density-dependent effects. International Journal for Parasitology 27, 1401-1409. 
Michael, E. \& Dunby, D.A.P. (1989). Density dependence in establishment, growth and worm

380 fecundity in intestinal helminthiasis: the population biology of Trichuris muris (Nematoda) 381 infection in CBA/Ca mice. Parasitology. 98, 451-458.

Mossinger, J \& Wenk, P. (1986). Fecundity of Litomosoides carinii (Nematoda, Filarioidea) in vivo and in vitro. Zeitschrift fuX r Parasitenkunde 72, 121-131.

Olivier, L. (1944). Acquired resistance in chickens, turkeys, and ring-necked pheasants to the gapeworm, Syngamus trachea. Journal of Parasitology. 30, 64-76.

Paterson, S. \& Viney, M.E. (2002). Host immune responses are necessary for density dependence in nematode infections. Parasitology. 125, 283-292.

Poulin, R. \& Morand, S. (2000). Parasite Body Size and Interspecific Variation in Levels of Aggregation among Nematodes. The Journal of Parasitology. 86, 642-647.

Richards, D. T. \& Lewis, j. w. (2001). Fecundity and egg output by Toxocara canis in the red fox, Vulpes vulpes. Journal of Helminthology 75, 157-164.

Sinniah, B. \& Subramaniam, K. (1991). Factors influencing the egg production of Ascaris 405 lumbricoides: relationship to weight, length and diameter of worms. Journal of Helminthology $\mathbf{6 5}$, 141-147.

Skorping, A., Read, A. F. \& Keymer, A. E. (1991). Life history covariation in intestinal nematodes of mammals. Oikos 60, 365-372.

412 Stear, M.J. \& Bishop, S.C. (1999). The curvilinear relationship between worm length and 413 fecundity of Teladorsagia circumcincta. International Journal for Parasitology. 29, 777-780. 
416 Stear, M.J., Bairden, K., Duncan, J.L., Holmes, P.H., McKellar, Q.A., Park, M., Strain, S., 417 Murray, M., Bishop, S.C., Gettinby, G. (1997). How hosts control worms. Nature. 389, 27.

Szalai, A. J. \& Dick, T. A. (1989). Differences in numbers and inequalities in mass and fecundity during the egg- producing period for Raphidascaris acus (Nematoda: Anisakidae). Parasitology 98, 489-495.

Tompkins, D.M. \& Hudson, P.J. (1999). Regulation of nematode fecundity in the ring-necked pheasant (Phasianus colchicus): not just density dependence. Parasitology. 118, 417-423.

Walker, M., Hall, A., Anderson, R.M., Basanez, M.G. (2009). Density-dependent effects on the weight of female Ascaris lumbricoides infections of humans and its impact on patterns of egg production. Parasites and Vectors. 2.

Wehr, E.E., 1937. Observations on the development of poultry gapeworm Syngamus trachea. Trans. Am. Microsc. Soc. 56., 72-78.

Williams, I.C. \& Newton, I. (1969). Intestinal helminths of the Bullfinch Pyrrhula pyrrhula 


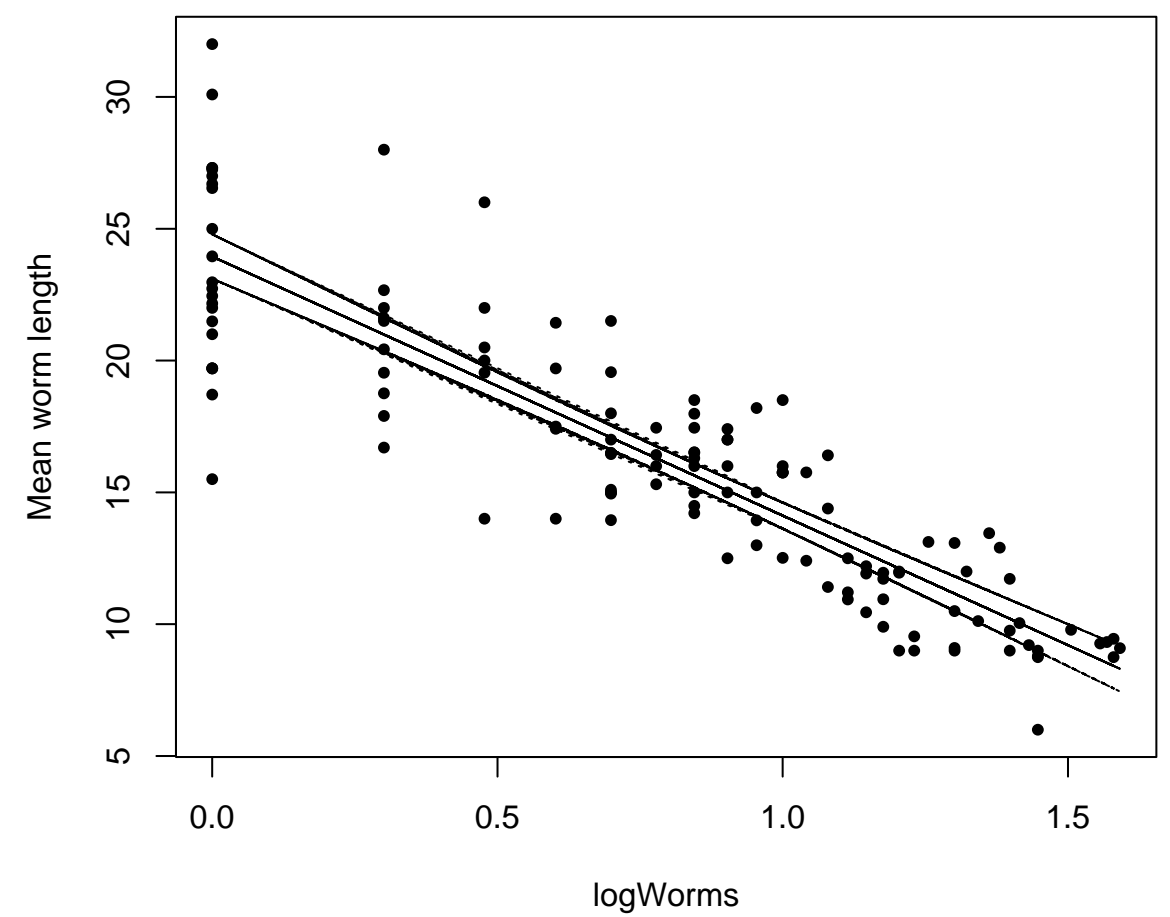

450

451 Figure 1 Relationship between log-mean number of worms and mean worm length for both species. Dashed line is $452 \quad 95 \%$ confidence interval.

453

454

455

456

457

458

459

460

461

462

463

464

465

466

467 

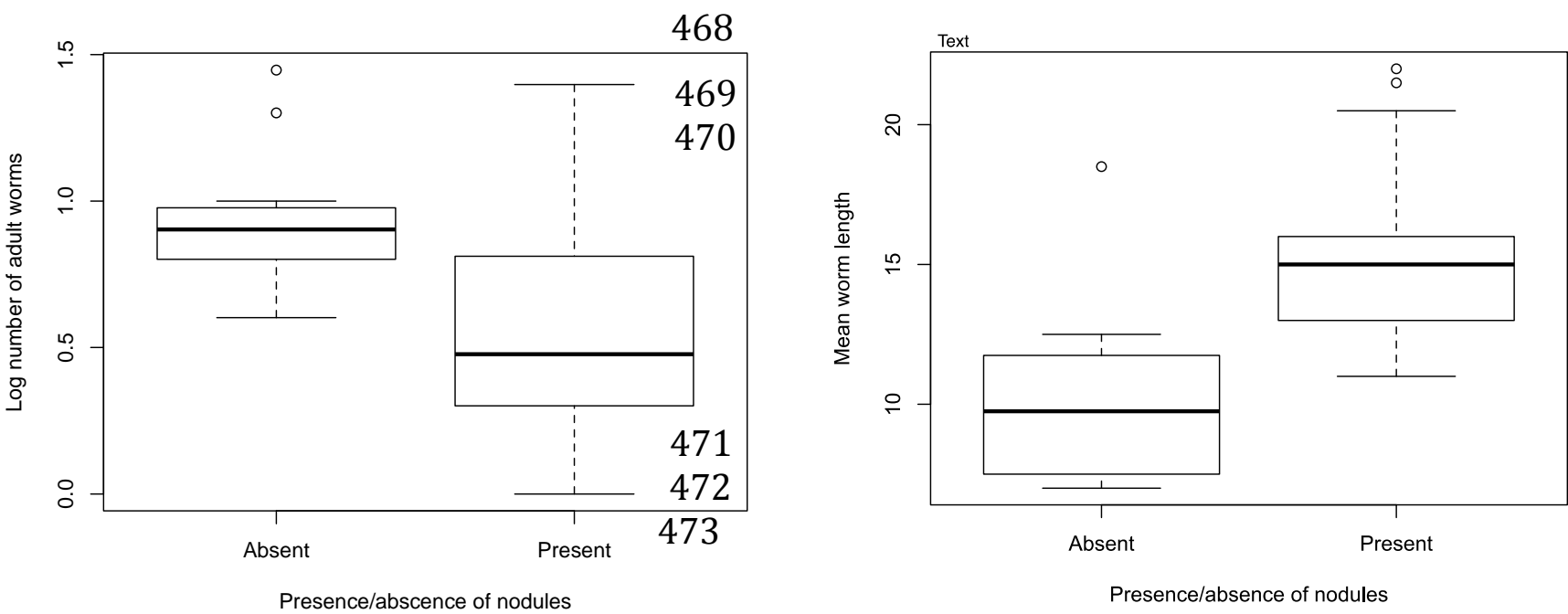

Figure2 Relationship between the presence of nodules and mean worm burden and mean worm length in Pheasants. 


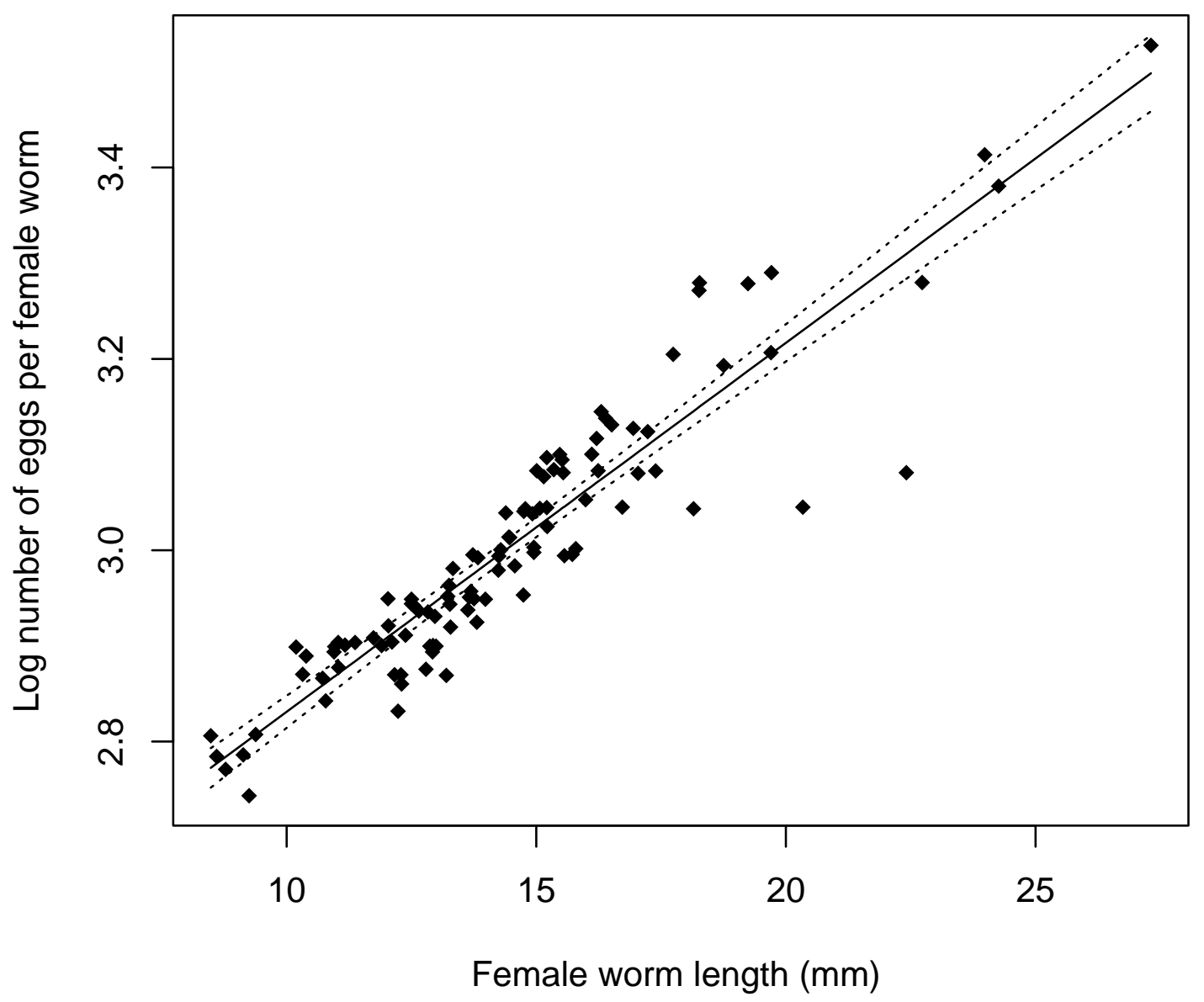

510

511

512 Figure 3? 